Advances in Cement Research Volume 29 Issue 10

Atomistic dynamics simulation to solve conformation of model PCE superplasticisers in water and cement pore solution

Hirata, Branicio, Ye et al.
Advances in Cement Research, 2017, 29(10), 418-428 http://dx.doi.org/10.1680/jadcr.16.00137 Paper 1600137 ite Qe

\title{
Atomistic dynamics simulation to solve conformation of model PCE superplasticisers in water and cement pore solution
}

\section{Tsuyoshi Hirata}

Nippon Shokubai Fellow, Research Division, Nippon Shokubai Co., Ltd, Osaka, Japan (corresponding author: tsuyoshi_hirata@shokubai.co.jp) (Orcid:0000-0003-0386-3525)

\section{Paulo Branicio}

Assistant Professor, University of Southern California, Los Angeles, CA, USA; Former Senior Scientist, Materials Science and Engineering, Institute of High Performance Computing, $A *$ Star, Connexis, Singapore (Orcid:0000-0002-8676-3644)

\section{Jun Ye}

Scientist, Materials Science and Engineering, Institute of High Performance Computing, A*Star, Connexis, Singapore (Orcid:0000-0003-1963-0865)

\section{Jianwei Zheng}

Deputy Department Director, Senior Scientist, Materials Science and

Engineering, Institute of High Performance Computing, A*Star, Connexis, Singapore

\section{Yoshikazu Tomike}

Researcher, Fine \& Specialty Chemicals Research Center, Nippon Shokubai Co., Ltd, Osaka, Japan

\section{Alex Lange}

Chair for Construction Chemistry, Technische Universität München, Garching, Germany

Johann Plank

Full Professor, Chair for Construction Chemistry, Technische Universität München, Garching, Germany

Michael Sullivan

Department Director, Materials Science and Engineering, Institute of High Performance Computing, A*Star, Connexis, Singapore

The working mechanism of polycarboxylate ether (PCE) type superplasticisers in concrete was studied from the point of view of conformational changes of the polymer simulated by molecular dynamics in pure water and cement pore solution. Three typical types of PCEs, namely a methoxy polyethyleneglycol monomethacrylate-sodium methacrylate copolymer (PCEM), a polyethyleneglycol mono allyl ether-sodium maleate copolymer (PCEA) and a polyethyleneglycol mono (3-methyl-3-butenyl) ether-sodium acrylate copolymer (PCEI) were investigated using large-scale atomistic molecular dynamics simulations. It was observed that the PCE polymers which possess negatively charged backbones were stretched in water due to electrostatic repulsion. However, they were found to be significantly shrunken and distorted in synthetic cement pore solution, depending on the polyethylene glycol (PEG) density along the backbone, resulting in the aggregation of PEG side chains due to the salting-out effect.

\author{
Notation \\ $D_{\text {end-end }}$ end-to-end distance \\ $\mathrm{d} n / \mathrm{d} c \quad$ refraction index increment \\ $M_{\mathrm{n}} \quad$ number average molecular weight \\ $M_{\mathrm{w}} \quad$ absolute weight average molecular weight \\ $R_{\mathrm{g}} \quad$ radius of gyration \\ $R_{\mathrm{h}} \quad$ hydrodynamic radius
}

\section{Introduction}

Polycarboxylate-based superplasticisers (PCEs) with polyethylene glycol (PEG) pendants can fluidise concrete with an extremely small amount of water and maintain the fluidity much longer than the conventional naphthalene sulfonate-type superplasticisers; this is because of their excellent dispersing force (Jeknavorian et al., 1997; Shonaka et al., 1997; Tsubakimoto et al., 1981). Hence, PCEs play an important role today in providing high-durability concrete, such as ultrahigh strength concrete (Kinoshita et al., 1997) and selfcompacting concrete (Okamura and Ouchi, 2003).

Polycarboxylate-based superplasticisers adsorb onto the cement surface with their negatively charged carboxyl groups present in the polymer backbone, while the PEG side chains stretch toward the water phase. It is believed that the excellent dispersion capability of PCEs is due to the steric repulsion of these PEG side chains. However, the correlation of PCE backbone structures with their dispersion performance is not well understood.

Many researchers have demonstrated that the steric repulsion of PCEs increases with increasing PEG side chain length or the adsorbed layer thickness (Houst et al., 2008; Kauppi et al., 2005; Kleshchanok and Lang, 2007; Nawa, 2006; Sakai and Daimon, 1997; Uchikawa et al., 1997; Yoshioka et al., 1997) and that the performance of PCE is affected by the extent of surface coverage as well (Flatt and Bowen, 2006).

Gay and Raphaël (2001) were the first to classify comb-shaped copolymers according to their grafting density and the relative lengths of the main and side chains. Later, based on a scaling law approach extracted from Gay and Raphaël's model, Borget et al. (2005) described the effects of salt-containing solutions on the microstructure and behaviour of polymethacrylateg-polyethylene oxide (PEO) comb polymers. Recently Flatt et al. (2009) elaborated on the adsorbed conformation of PCEs, which they regarded as non-ionic comb-like polymers. 
Advances in Cement Research

Volume 29 Issue 10
Atomistic dynamics simulation to solve

conformation of model PCE

superplasticisers in water and cement

pore solution

Hirata, Branicio, Ye et al.
Based on the blob model they predicted the polymer conformation in aqueous solution and when adsorbed on the surface of a substrate. The calculated properties - that is, polymer radius of gyration, adsorbed layer thickness, surface coverage and steric repulsion force - were in good agreement with experimental results measured by atomic force microscope on a flat calcium-silicate-hydrate $(\mathrm{C}-\mathrm{S}-\mathrm{H})$ substrate in calcium hydroxide $\left(\mathrm{Ca}(\mathrm{OH})_{2}\right)$ solution.

These early studies provided very useful insights; nevertheless, they need to be further extended to advance the understanding of superplasticisers. For instance, the PCE polymer structures considered in the studies were limited. The charges and interactions were absent in the models. The aggregation of PEG side chains was also not considered.

In this paper, atomistic molecular dynamics (MD) simulations have been used to study polymer conformations in various environments and the conformational changes can be characterised in detail by analysing the time evolution of the systems provided by the simulation trajectory. MD simulations have been applied in studies of the conformation of PEO and polypropylene oxide (PPO) in various solvents. Recently, MD simulations have been applied to concrete. Mohan et al. (2014) showed that the addition of $1 \sim 2 \%$ PCE superplasticiser has no effect on the mechanical properties of C-S-H. Mishra et al. (2012) studied the adsorption of PCE oligomers on dry and hydroxylated tricalcium silicate $\left(3 \mathrm{CaO}-\mathrm{SiO}_{2}\right.$ or $\left.\mathrm{C}_{3} \mathrm{~S}\right)$ surfaces and found out that PCEs have higher adsorption energy on dry $\mathrm{C}_{3} \mathrm{~S}$ compared to on a hydroxylated $\mathrm{C}_{3} \mathrm{~S}$ surface. Shu et al. (2016) investigated the influence of backbone stiffness on the polymer conformation. However, to the best of the present authors' knowledge, there is no MD simulation study which reports on the conformation of PCEs in cement pore solution.

Here, the conformations of three common types of PCEs in water and synthetic cement pore solution are reported based on results of large-scale atomistic MD simulations. The PCEs used in this work were a methacrylate type, an allyl ether type and an isoprenyl ether type, with ethylene oxide (EO) unit numbers in the side chain of 25,34 and 25 , respectively. They are denoted as PCEM-25, PCEA-34 and PCEI-25. These PCEs have different monomer composition ratios and absolute molar masses $\left(M_{\mathrm{w}}\right)$. However, they showed the same flow value in the mini-slump test at different dosages. PCEA-34 is an alternating copolymer with $\mathrm{ABAB}$ sequence, whereas PCEM-25 is a random copolymer (Pickelmann et al., 2015), where A and B refer to the monomer units containing the carboxylic group and PEG side chain, respectively. PCEI-25 is considered as a block copolymer with ABA, ABAA and AA blocks, as evidenced by ${ }^{13} \mathrm{C}$ nuclear magnetic resonance (NMR) spectroscopy (Plank et al., 2016). This is consistent with experiments showing that the isoprenyloxy polyethylene glycol (IPEG) macromonomers hardly polymerise with each other.
To understand the effect of the monomer sequence, two kinds of PCEI-25 were constructed with the same monomer molar ratio (grafting ratio) and the same $M_{\mathrm{w}}$. The first is a random copolymer and is denoted as PCEI-25-I. The second is an alternating copolymer denoted as PCEI-25-II.

Various conformational properties, such as radius of gyration $\left(R_{\mathrm{g}(\mathrm{MD})}\right)$, hydrodynamic radius $\left(R_{\mathrm{h}(\mathrm{MD})}\right)$ and end-to-end distance $\left(D_{\text {end-end(MD) }}\right)$, were calculated during MD simulations and compared with experimental results.

Lastly, the conformational change of the multi-branch PEG with different degrees of branching was studied in solutions to observe the congestion effect of PEG chains on the aggregation.

\section{Materials}

\section{Cement}

The cement used in this study was an ordinary Portland cement (CEM I $52.5 \mathrm{~N}$ Milke®classic from Heidelberg Cement, Geseke plant, Germany). Its phase composition as determined by quantitative X-ray diffraction (Bruker D8 advance instrument, software Topas 4.0) is presented in Table 1. The specific surface area of $3299 \mathrm{~cm}^{2} / \mathrm{g}$ was measured using a Blaine instrument (Toni Technik, Berlin, Germany). An average particle size ( $d_{50}$ value) of $12.02 \mu \mathrm{m}$ was determined by way of laser granulometry Cilas 1064 (Cilas, Marseille, France), and the density was $3 \cdot 16 \mathrm{~g} / \mathrm{cm}^{3}$ as measured by a Helium pycnometer (Quantachrome, Odelzhausen, Germany).

\section{PCE copolymers}

The chemical structures of the PCE samples studied, PCEM-25, PCEI-25 and PCEA-34, are shown in Figure 1. Their individual synthesis methods have been described previously (Hirata et al., 2000; Lange et al., 2012; Yamamoto

Table 1. Phase composition of CEM I 52.5 N sample

\begin{tabular}{lr} 
Phase & wt $\%$ \\
\hline$C_{3} S, m$ & $70 \cdot 1$ \\
$C_{2} S, m$ & $11 \cdot 0$ \\
$C_{3} A, C$ & $5 \cdot 1$ \\
$C_{3} A, O$ & $2 \cdot 1$ \\
$C_{4} A F$, o & $2 \cdot 5$ \\
Free lime (Franke) & $0 \cdot 9$ \\
Periclase (MgO) & $0 \cdot 0$ \\
Anhydrite & $2 \cdot 5$ \\
Hemihydrate & $0 \cdot 3$ \\
Dihydrate & $0 \cdot 4$ \\
Calcite & $3 \cdot 3$ \\
Quartz & $0 \cdot 7$
\end{tabular}

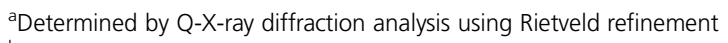

${ }^{b}$ Determined by thermogravimetry 
Atomistic dynamics simulation to solve

conformation of model PCE

superplasticisers in water and cement

pore solution

Hirata, Branicio, Ye et al.

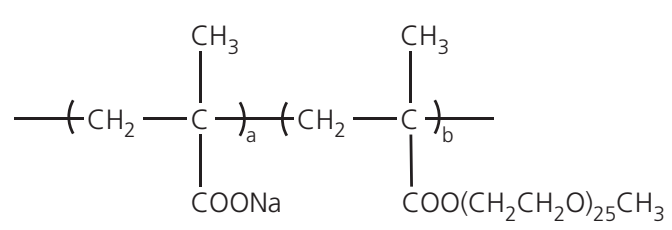

(a)

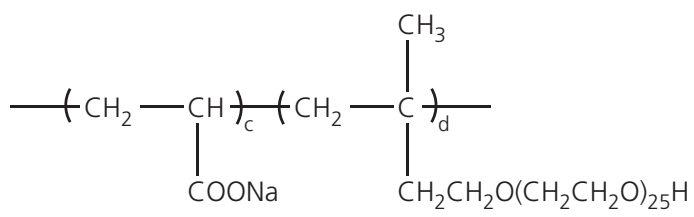

(b)

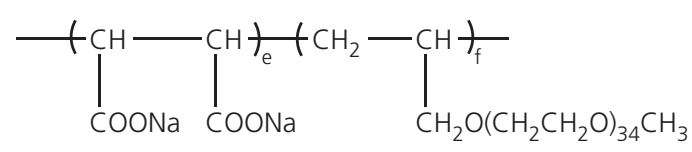

(c)

Figure 1. Chemical structures of the PCE samples studied: (a) PCEM-25; (b) PCEI-25; (c) PCEA-34

et al., 2004). The properties of the synthesised polymers are summarised in Table 2.

The $M_{\mathrm{w}}$, the polymer content (monomer conversion) and the polydispersity index (PDI) were determined by size exclusion chromatography (SEC; Waters Alliance 2695 from Waters, Eschborn, Germany) equipped with refractive index (RI) detector 2414 (Waters, Eschborn, Germany) and a three-angle dynamic light-scattering detector (mini Dawn from Wyatt Technologies, Santa Barbara, CA, USA): prior to application on the columns, the polymer solutions were filtered through a $0.2 \mu \mathrm{m}$ filter. The polymers were separated on an Ultrahydrogel precolumn and three Ultrahydrogel (120, 250 and 500) columns (Waters, Eschborn, Germany) using $0 \cdot 1 \mathrm{M}$ aqueous sodium nitrate $\left(\mathrm{NaNO}_{3}\right)$ solution (adjusted to $\mathrm{pH} 12.0$ with sodium hydroxide $(\mathrm{NaOH})$ ) as an eluent at a flow rate of $1.0 \mathrm{ml} / \mathrm{min}$. The value of refraction index increment $(\mathrm{d} n / \mathrm{d} c)$ used to calculate $M_{\mathrm{w}}$ and $M_{\mathrm{n}}$ for all polymers is $0 \cdot 135 \mathrm{ml} / \mathrm{g}$ (value for PEO) (Teresa et al., 2001).

The SEC spectra of the PCE samples are displayed in Figure 2. The polymer content (percentage of monomers converted to polymer) was determined by the area $(\%)$ of the polymer profile in the RI diagram.

It has to be noted that polymer PCEM-25 showed extremely strong scattering intensity at very high $M_{\mathrm{w}}$ (elution volume $\sim 15 \mathrm{ml}$ ), which may result from a crosslinked PCE caused by PEG di-methacrylate present in the macromonomer, or by peroxide on PEG chains during polymerisation (Hirata et al., 2000; Paas et al., 2015). However, it is negligible in the simulation because of a quite low content of $0.7 \mathrm{wt} \%$. Furthermore, PCE sample PCEA-34 contains a noticeable amount of non-reacted allyl ether macromonomer, but is simulated as an alternating copolymer.

Figure 3 illustrates the initial structure of the PCEs before geometric optimisation. All polymer models are constructed by way of the polymer builder function of the Materials Studio package. In PCEA the side chains line up much more densely along the backbone than in PCEM and PCEI because of an alternating copolymer.

In all three PCE samples of PCEM-25, PCEI-25 and PCEA34, the weight ratio of PEG macromonomer/carboxylic monomer was optimised for best dispersion. For example, the weight ratio of the monomers in PCEM-25 was 75/25 (PEG monomer/acid monomer), which is in good agreement with the value that has been suggested by Winnefeld et al. (2007) as well. In this paper, the dosages applied in the cement paste tests were all converted to the values for the pure polymers without residual monomers to compare the effects of the polymers themselves.

The $R_{\mathrm{h}(\mathrm{MD})}$ were verified by the hydrodynamic radius of $R_{\mathrm{h}(\mathrm{VIS})}$ measured. The $R_{\mathrm{h}(\mathrm{VIS})}$ were determined by a Viscotek

Table 2. Monomer composition and analytical data of the PCE samples

\begin{tabular}{|c|c|c|c|c|c|c|}
\hline \multirow[b]{3}{*}{ PCE-Pa } & \multirow[b]{3}{*}{$M_{\mathrm{w}}^{\mathrm{b}}$} & \multirow[b]{3}{*}{$\tau^{\mathrm{c}}: \mathrm{mol} \%$} & \multicolumn{2}{|c|}{ Composition: wt $\%^{d}$} & \multirow[b]{3}{*}{ Polymer content ${ }^{\mathrm{b}}: \%$} & \multirow[b]{3}{*}{ Polydispersity index, PDI $\left(M_{\mathrm{w}} / M_{\mathrm{n}}\right)$} \\
\hline & & & PEG & Carboxylic & & \\
\hline & & & Monomer & Monomer & & \\
\hline PCEM-25 & 68800 & 21 & 75 & 25 & $96 \cdot 1$ & $2 \cdot 2$ \\
\hline PCEI-25 & 93800 & 31 & 85 & 15 & $92 \cdot 2$ & $2 \cdot 6$ \\
\hline PCEA-34 & 63100 & 50 & 91 & 9 & $70 \cdot 4$ & $2 \cdot 8$ \\
\hline
\end{tabular}

${ }^{a} P$ : number of ethylene oxide (EO) units

${ }^{b}$ Determined by SEC

${ }^{\mathrm{c}}$ Grafting molar ratio

${ }^{d}$ Weight ratio of monomers used in the polymerisation process 
Advances in Cement Research Volume 29 Issue 10
Atomistic dynamics simulation to solve

conformation of model PCE

superplasticisers in water and cement

pore solution

Hirata, Branicio, Ye et al.

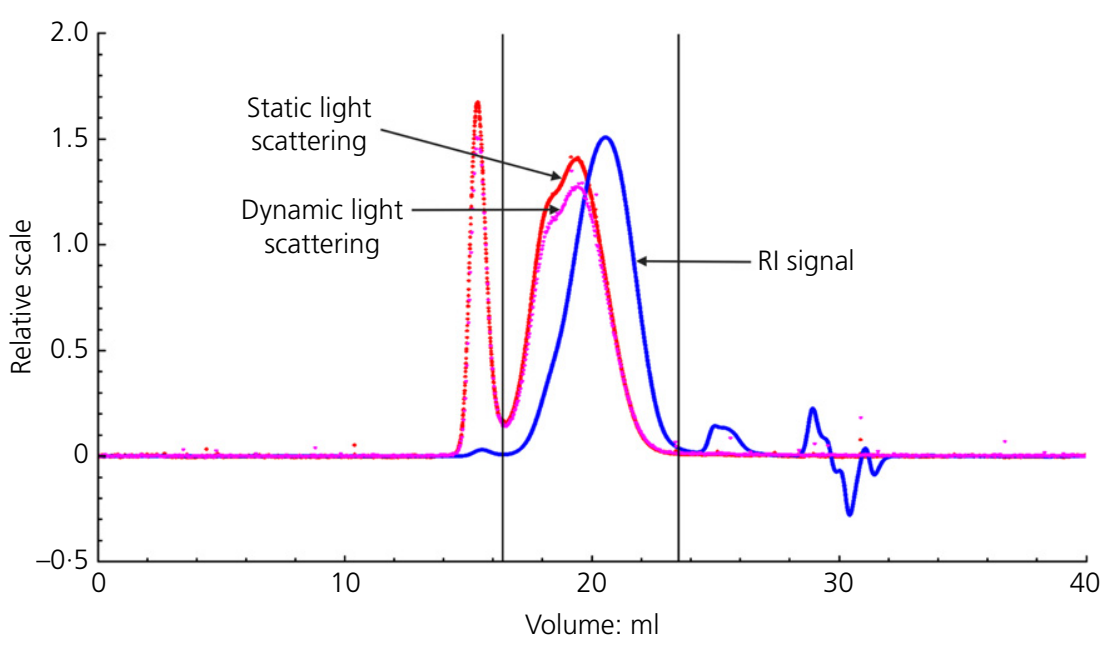

(a)

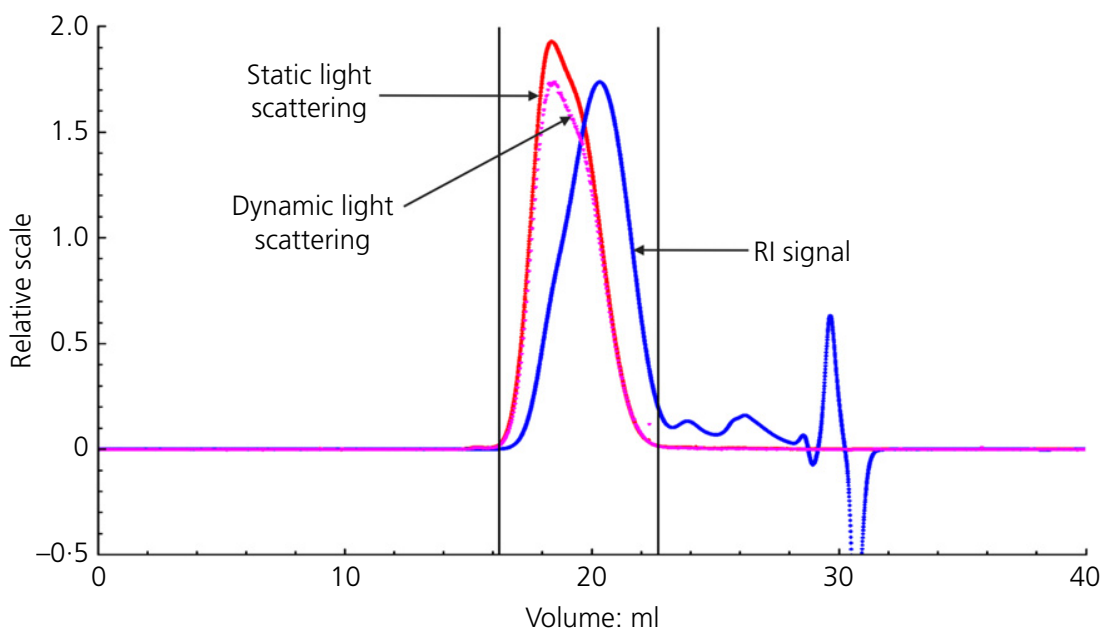

(b)

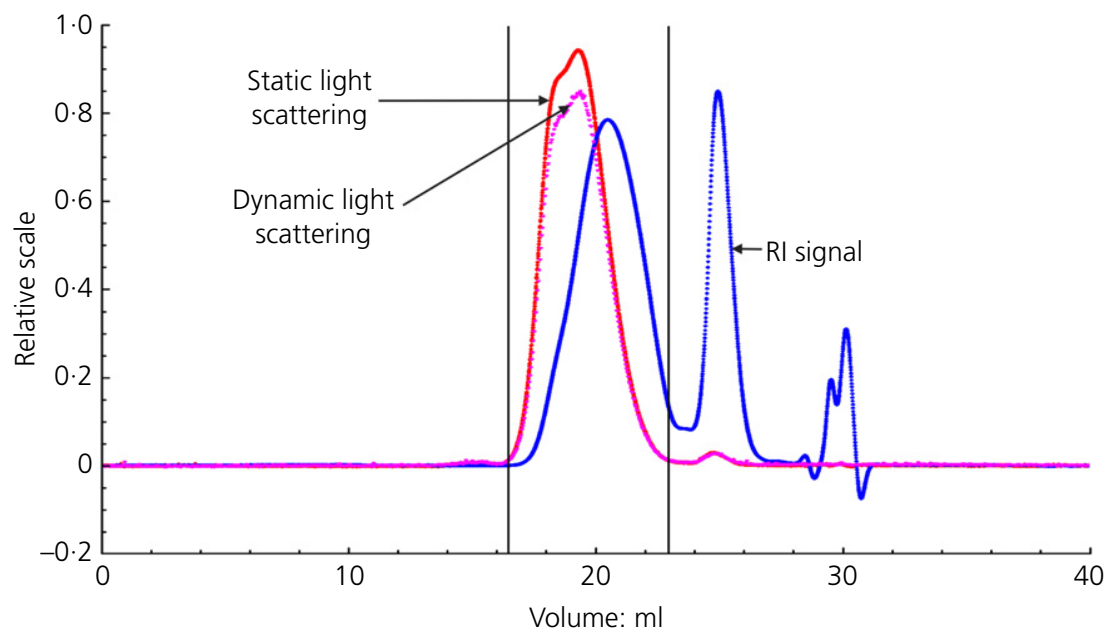

(c)

Figure 2. SEC spectra of the PCE samples: (a) PCEM-25; (b) PCEI-25; (c) PCEA-34 


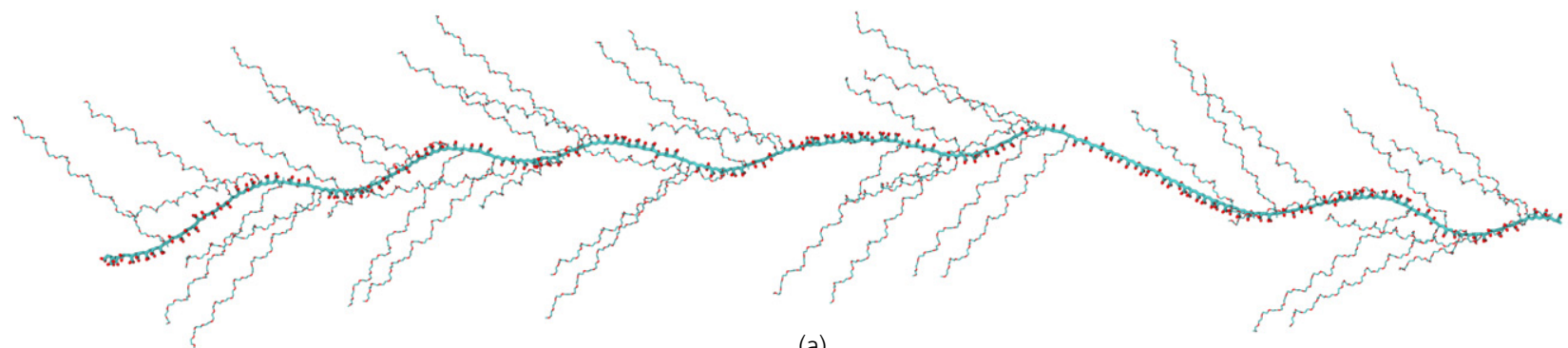

(a)

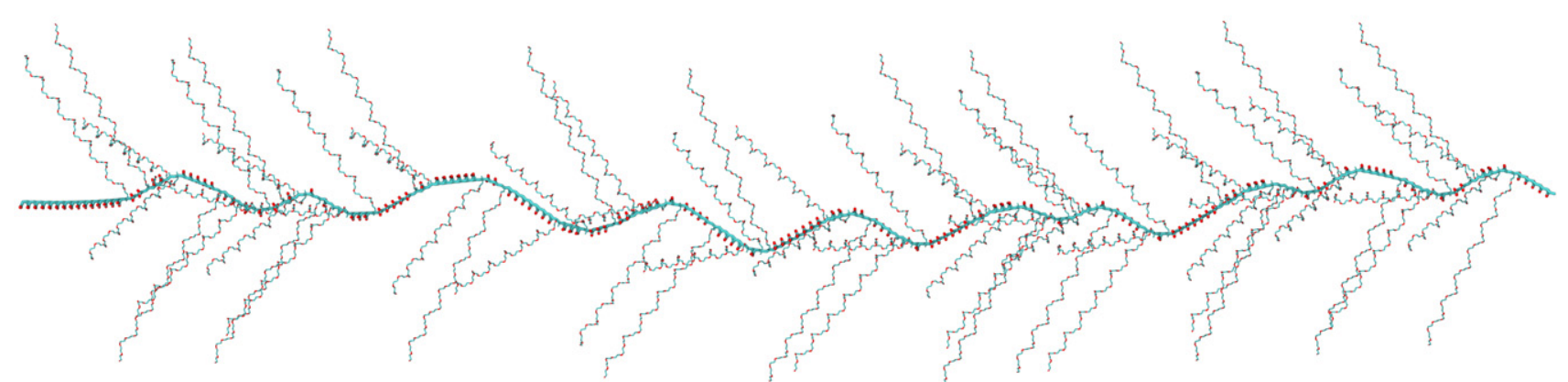

(b)

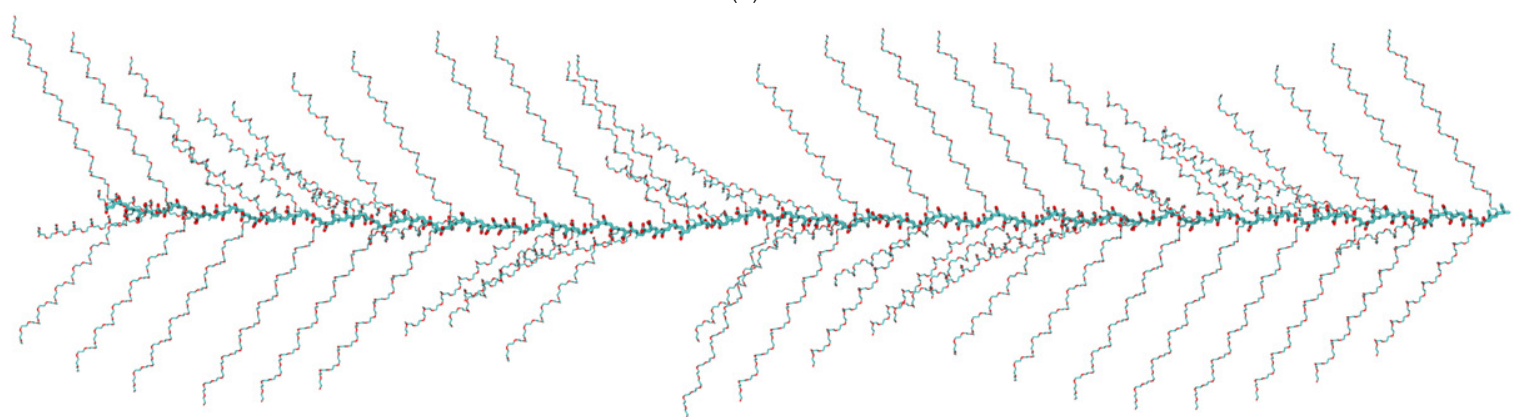

(c)

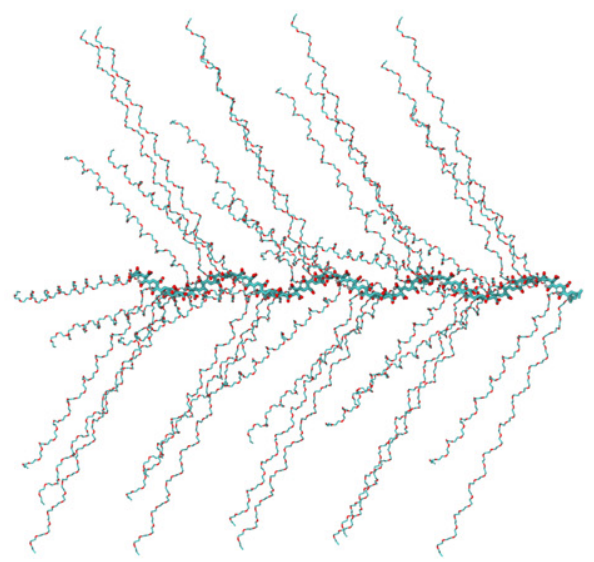

(d)

Figure 3. Initial structures of the PCE samples before geometric optimisation, with specific bond angles and interatomic distances which are inherent in each atom: (a) PCEM-25 with 9921 atoms; (b) PCEI-25-I with 13999 atoms; (c) PCEI-25-II with 13999 atoms; (d) PCEA-34 with 9816 atoms

GPC Max VE 2001 (Malvern Instruments Ltd, UK) equipped with a triple detector array (TDA 302, Malvern Instruments Ltd, UK) - that is an RI detector, a viscometer and two light-scattering detectors (low angle and right angle, $670 \mathrm{~nm}$ ). The $R_{\mathrm{h}(\mathrm{VIS})}$ were calculated by the Einstein equation defining the relationship between the polymer viscosity and $M_{\mathrm{w}}$ using 


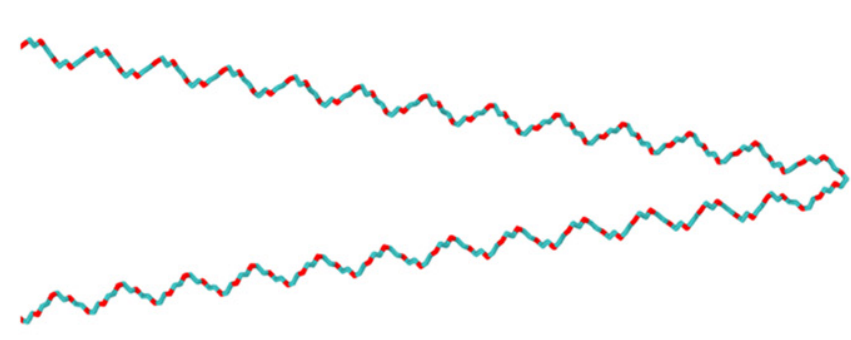

(a)

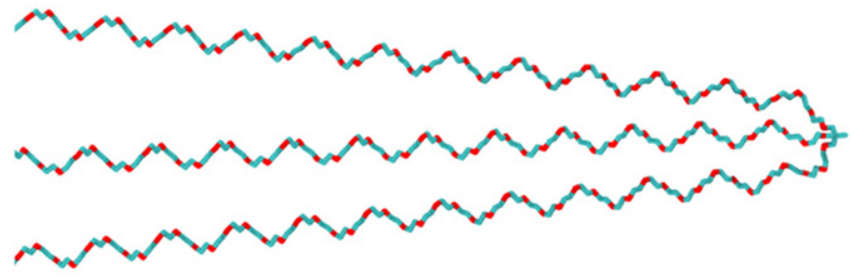

(b)

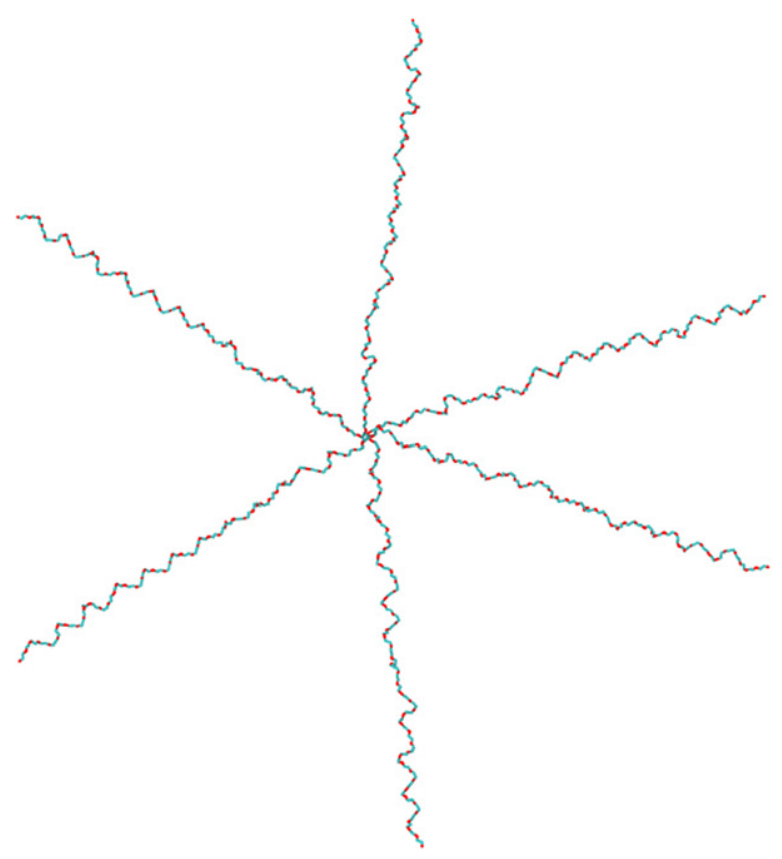

(c)

Figure 4. Initial structures of (a) PEG-100, (b) TMP-150 and (c) Sorbitol-300. All hydrogen atoms are hidden for clarity

statistical light scattering. The PCE samples were separated on a TSK guard column $\alpha$ and three TSK gel $(\alpha-5000, \alpha-4000$ and $\alpha-3000$ ) columns (Tosoh Corporation, Tokyo, Japan). As the mobile phase, a mixed solvent of acetonitrile and water $\left(\mathrm{CH}_{3} \mathrm{CN} / \mathrm{H}_{2} \mathrm{O}=80 / 20 \mathrm{wt}\right.$ ratio $)$ containing $0 \cdot 10 \mathrm{M}$ boric acid $\left(\mathrm{H}_{3} \mathrm{BO}_{3}\right) / 0 \cdot 05 \mathrm{M}$ sodium hydroxide $(\mathrm{NaOH})$ was used at $40^{\circ} \mathrm{C}$ and a flow rate of $0.8 \mathrm{ml} / \mathrm{min}$. Prior to application on the columns, the polymer solutions were filtered through a $0.2 \mu \mathrm{m}$ filter. The value of $\mathrm{d} n / \mathrm{d} c$ used to calculate $M_{\mathrm{w}}$ for all polymers is $0.135 \mathrm{ml} / \mathrm{g}$ (value for polyethylene oxide) (Teresa et al., 2001).

\section{Multi-branch PEG}

To understand the aggregation of PEG side chains in cement pore solution, three types of multi-branch PEGs were built up and their conformational changes in synthetic cement pore solution were simulated. The PEG compounds used were PEG-100, TMP-150 and sorbitol-300, where PEG-100 is a linear polymer with 100 EO units, TMP-150 is a trimethylol propane EO adduct having three PEG branches each, with $50 \mathrm{EO}$ units linking to the end carbon of propane through an ether bond, and sorbitol-300 is a sorbitol EO adduct containing six PEG branches each with 50 EO units linking to each backbone carbon atom of sorbitol through an ether bond. The initial structures are shown in Figure 4.

The simulation results of $R_{\mathrm{h}(\mathrm{MD})}$ were verified by measuring the hydrodynamic radius of $R_{\mathrm{h} \text { (DLS) }}$ obtained by dynamic light-scattering (DLS) measurements. The $R_{\mathrm{h}(\mathrm{DLS})}$ values were determined by Zetasizer Nano ZSP (Malvern Instruments Ltd, UK), which utilises the Stokes-Einstein equation that defines the relationship between the hydrodynamic radius of a sample and its speed due to Brownian motion using DLS. The polymer concentration was $0.5 \mathrm{wt} \%$ in solution and the temperature was $25^{\circ} \mathrm{C}$.

The PEG compounds were synthesised by EO addition to the corresponding alcohols using potassium hydroxide $(\mathrm{KOH})$ as a catalyst.

\section{Experimental and simulation procedures}

Performance test with cement using 'mini slump' test

For the determination of the paste flow, a 'mini slump' test was utilised and carried out as follows. First, a constant waterto-cement $(w / c)$ ratio of $0 \cdot 3$ was chosen. At this $w / c$ ratio, the dosages of the polymers required to reach a spread of $26 \pm 0.5 \mathrm{~cm}$ were determined. Generally, the polymer was dissolved in the required amount of mixing water placed in a porcelain cup. The amount of water contained in the polymer solution was subtracted from the amount of mixing water. Next, within $5 \mathrm{~s}, 350 \mathrm{~g}$ of cement were added to the mixing water and agitated manually for $1 \mathrm{~min}$, then rested for $1 \mathrm{~min}$ without stirring. This was followed by intensive stirring for another $2 \mathrm{~min}$. The cement paste was immediately poured into a Vicat cone (height $40 \mathrm{~mm}$, top diameter $70 \mathrm{~mm}$, bottom diameter $80 \mathrm{~mm}$ ) placed on a glass plate and the cone was 
vertically lifted. The resulting spread of the paste was measured twice, the second measurement being at a $90^{\circ}$ angle to the first, and averaged to give the spread value. All tests were carried out at $22^{\circ} \mathrm{C}$.

\section{Molecular dynamics simulations}

The synthetic cement pore solution used in the simulations was generated using the following amount of salts: $1.72 \mathrm{~g} / \mathrm{l}$ gypsum $\left(\mathrm{CaSO}_{4} 2 \mathrm{H}_{2} \mathrm{O}\right), 6.959 \mathrm{~g} / \mathrm{l}$ sodium sulfate $\left(\mathrm{Na}_{2} \mathrm{SO}_{4}\right), 4.757 \mathrm{~g} / \mathrm{l}$ potassium sulfate $\left(\mathrm{K}_{2} \mathrm{SO}_{4}\right)$ and $7 \cdot 12 \mathrm{~g} / 1$ potassium hydroxide $(\mathrm{KOH})(\mathrm{pH}=13 \cdot 1)$. The salts are assumed to be completely dissociated in water. Based on this assumption the exact molar concentrations of $\mathrm{Ca}^{2+}, \mathrm{SO}_{4}^{2-}, \mathrm{Na}^{+}, \mathrm{K}^{+}$and $\mathrm{OH}^{-}$are calculated to be: $\mathrm{Ca}^{2+}: 0 \cdot 010 \mathrm{M}, \mathrm{Na}^{+}: 0 \cdot 098 \mathrm{M}, \mathrm{K}^{+}: 0 \cdot 181 \mathrm{M}, \mathrm{SO}_{4}^{2}$ -: $0.086 \mathrm{M}$ and $\mathrm{OH}^{-}: 0.127 \mathrm{M}$. For simulation purposes, the molar concentrations are converted to volumetric concentrations: $\mathrm{Ca}^{2+}: 6.087 \times 10^{-3} / \mathrm{nm}^{3}, \mathrm{Na}^{+}: 5.901 \times 10^{-2} / \mathrm{nm}^{3}, \mathrm{~K}^{+}$: $0 \cdot 109 / \mathrm{nm}^{3}, \quad \mathrm{SO}_{4}^{2-}: \quad 5.203 \times 10^{-2} / \mathrm{nm}^{3}$ and $\mathrm{OH}^{-}$: $7 \cdot 642 \times 10^{-2} / \mathrm{nm}^{3}$.

The time evolution of the conformations of the polymers were obtained by classical MD simulations using the Gromacs package (Berendsen et al., 1995; Hess et al., 2008; Lindahl et al., 2001; Spoel et al., 2005). Simulations were performed using the $N V T$ ensemble (constant temperature, volume and number of atoms) at room temperature $(300 \mathrm{~K})$ with a time step of 2 fs. The Lincs algorithm (Hess et al., 1997) and its parallel version P-Lincs (Hess, 2008) are applied to constrain bonds involving light atoms such as hydrogen. Prior to each run, energy minimisation and a $5 \mathrm{~ns}$ dynamics relaxation under the grand canonical ensemble $N P T$ with pressure $P=1$ bar and temperature $(300 \mathrm{~K})$ was applied, followed by about $200 \sim 350 \mathrm{~ns}$ NVT runs. The visual molecular dynamics (VMD) visualisation package (Humphrey et al., 1996) was used to analyse various properties such as radius of gyration (whole polymer), end-to-end distance (backbone and side chains) and hydrodynamic radius for the whole polymer based on MD trajectories was saved every 10000 steps (20 ps) and averaged in the last $30 \mathrm{~ns}$ of the simulations. The 'optimised potentials for liquid simulations' (OPLS) all atom (Jorgensen et al., 1996) force field was applied for all polymers and ions, except for $\mathrm{OH}^{-}$and $\mathrm{SO}_{4}^{2-}$. Force field parameters for $\mathrm{OH}^{-}$ and $\mathrm{SO}_{4}^{2-}$ ions were taken from the 'chemistry at Harvard macromolecular mechanics' (Charmm) force field.

\section{Results and discussion}

\section{Dispersing performance of PCEs}

To obtain an initial cement paste flow of $26 \pm 0.5 \mathrm{~cm}$, the PCE dosages measured were $0 \cdot 14 \mathrm{wt} \%$ (PCEM-25), $0 \cdot 10 \mathrm{wt} \%$ (PCEI-25) and $0 \cdot 14 \mathrm{wt} \%$ (PCEA-34). This result signifies that the PCE polymer PCEI-25 possesses the highest dispersing ability of all these samples tested.

\section{Polymer conformation in pure water and in synthetic} cement pore solution

The typical time evolution of various conformation properties in water and synthetic cement pore solution for PCEM-25, PCEI-25-I, PCEI-25-II and PCEA-34 oscillate around a certain value in the range of about $200 \sim 300 \mathrm{~ns}$, indicating the system has reached a steady state and is well equilibrated.

The various conformation properties obtained are listed in Table 3 . The radii of gyration $\left(R_{\mathrm{g}(\mathrm{mf})}\right)$ predicted by the meanfield model (Flatt et al., 2009; Gay and Raphaël, 2001) and the hydrodynamic radii of $R_{\mathrm{h} \text { (VIS) }}$ measured are also listed for comparison. The snapshots of the last frame for all PCEs are shown in Figure 5.

First, it can be seen from Figure 5 that all the polymer molecules have become shrunken and distorted in the synthetic cement pore solution. Comparing PCEI-25-I (random copolymer) and PCEI-25-II (alternating-like copolymer), it can be seen how the aggregation of the adjacent PEGs affects the conformation of the backbone in synthetic cement pore solution. Namely, the backbone of PCEI-25-I is surprisingly shrunken and distorted by the strong aggregation of adjacent PEGs, as well as the salting-out effect of the backbone, whereas PCEI-25-II is shrunken probably because of the salting-out effect on the backbone. Bailey and Callard (1959) showed that the solubility of PEO in water should be lowered by the presence of salts and is drastically reduced by a $\mathrm{pH}$ level beyond 12. These salting-out effects are reflected by an increase of PEG hydrophobicity in solution, resulting in a high degree of entanglement of the polymer chains. Certainly, for all PCEs, the end-to-end distances for the PEG side chains $\left(D_{\text {end-end(MD) }}^{\text {sidechains }}\right)$ are a bit smaller in cement pore solution than in water due to the salting-out effect (Table 3 ).

Early reports also showed that PEG molecules easily aggregate with each other by hydrogen bonds (Begum and Matsuura, 1997; Linegar et al., 2010) and PEG side chains would entangle due to close proximity (de Gennes, 1987; Flatt and Bowen, 2006). The magnitude of the aggregation of PEG side chains is found to follow the trend: PCEA-34 (proximity distance, $0.54 \mathrm{~nm})>$ PCEM-25 $(0.58 \mathrm{~nm}) \approx$ PCEI- $25-\mathrm{I}(0.59 \mathrm{~nm})>$ PCEI$25-\mathrm{II}(0 \cdot 72 \mathrm{~nm})$. Here, the proximity distances were determined from the initial polymer structure, as shown in Figure 3. In addition, the relevant PEG radii of gyration of $1 \cdot 31 \pm 0 \cdot 28 \mathrm{~nm}$ $(P=25)$ and $1.56 \pm 0.35 \mathrm{~nm}(P=34)$, as calculated by the relational expression with the molecular weight in water according to Devanand and Selser (1991), are much longer than half of the proximity distances, thus strongly suggesting the possibility of an interaction between PEG side chains.

Comparing the end-to-end distances of the polymer backbones ( $D_{\text {end }}^{\text {backond(MD) }}$ ), those of all PCEs in water are larger than those in synthetic cement pore solution (Table 3). This indicates that in water the PCE backbones are considerably 
$-1 \mathrm{~nm} \quad$ Water

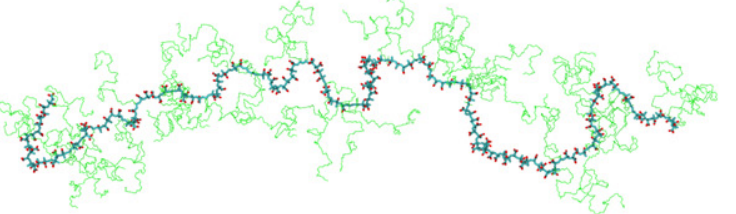

(a)

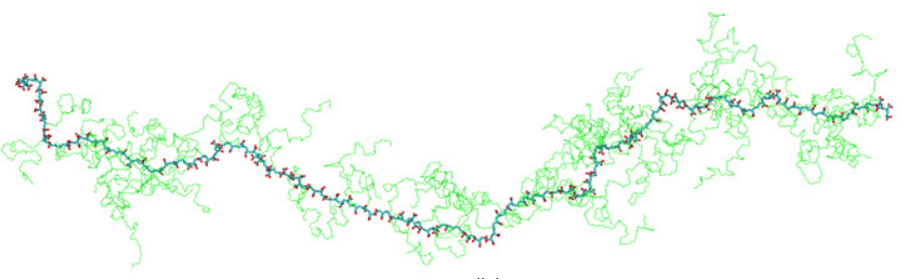

(b)

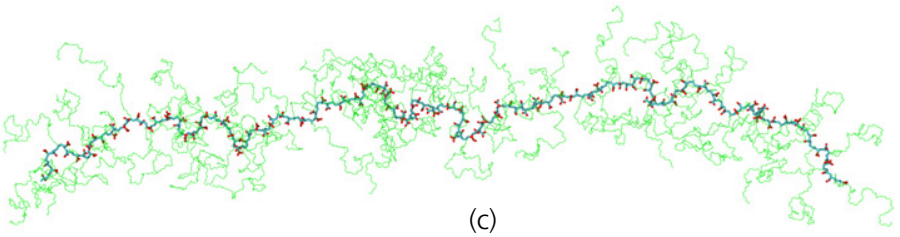

(c)

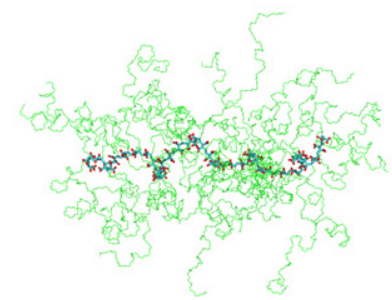

(d)
Synthetic cement pore solution

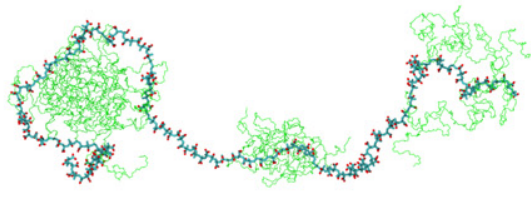

(e)

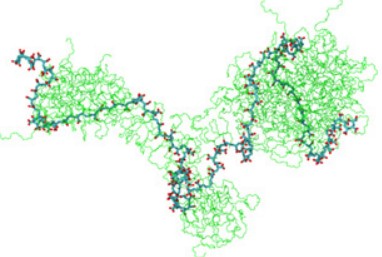

(f)

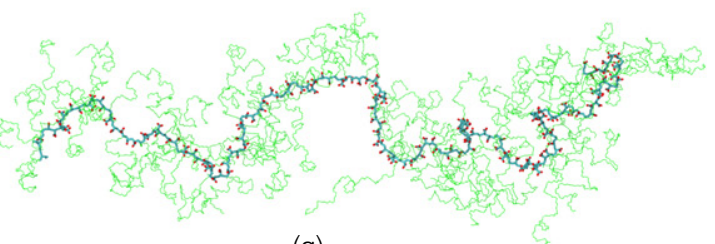

(g)

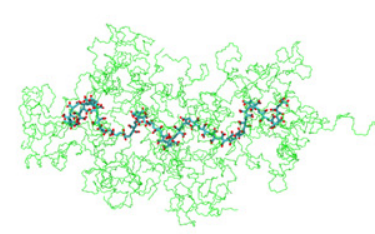

(h)

Figure 5. Conformations of PCEs in water and synthetic cement pore solution. (a), (b), (c) and (d) show PCEM-25, PCEI-25-I, PCEI-25-II and PCEA-34 in water, respectively. (e), (f), (g) and (h) show PCEM-25, PCEI-25-I, PCEI-25-II and PCEA-34 in synthetic cement pore solution, respectively

Table 3. Polymer properties in water and synthetic cement pore solutions calculated from molecular dynamics simulations

\begin{tabular}{|c|c|c|c|c|c|c|}
\hline Polymer type & $D_{\text {end-end(MD) }}^{\text {backone }}: \mathrm{nm}$ & $D_{\text {end-end(MD) }}^{\text {sidechains }}{ }^{\mathrm{a}}: \mathrm{nm}$ & $\boldsymbol{R}_{\mathrm{g}(\mathrm{MD})}: \mathrm{nm}$ & $\left.R_{\mathrm{g}(\mathrm{mf})}\right)^{\mathrm{b}}: \mathrm{nm}$ & $R_{\mathrm{h}(\mathrm{MD})}: \mathrm{nm}$ & $R_{\mathrm{h}(\mathrm{VIS})} \mathrm{c}: \mathrm{nm}$ \\
\hline PCEM-25 (water) & $28 \cdot 2$ & $2 \cdot 64 \pm 0 \cdot 30$ & $9 \cdot 1$ & $9 \cdot 8$ & $5 \cdot 8$ & - \\
\hline PCEI-25-I (water) & $34 \cdot 0$ & $2 \cdot 63 \pm 0 \cdot 37$ & $10 \cdot 4$ & $11 \cdot 8$ & $6 \cdot 3$ & \\
\hline PCEI-25-II (water) & $31 \cdot 0$ & $2 \cdot 62 \pm 0 \cdot 37$ & $10 \cdot 0$ & $11 \cdot 8$ & $6 \cdot 4$ & - \\
\hline PCEA-34 (water) & $9 \cdot 0$ & $3 \cdot 20 \pm 0 \cdot 50$ & 3.9 & $8 \cdot 5$ & $3 \cdot 8$ & - \\
\hline PCEM-25 (cement) & $16 \cdot 3$ & $2 \cdot 44 \pm 0 \cdot 27$ & $6 \cdot 3$ & - & $4 \cdot 0$ & $5 \cdot 5$ \\
\hline PCEI-25-I (cement) & $10 \cdot 7$ & $2 \cdot 60 \pm 0.45$ & $4 \cdot 6$ & - & $3 \cdot 7$ & - \\
\hline PCEI-25-II (cement) & $23 \cdot 0$ & $2 \cdot 60 \pm 0 \cdot 22$ & $7 \cdot 5$ & - & $5 \cdot 7$ & $7 \cdot 9$ \\
\hline PCEA-34 (cement) & $8 \cdot 2$ & $3 \cdot 16 \pm 0 \cdot 35$ & $3 \cdot 8$ & - & $3 \cdot 7$ & $2 \cdot 9$ \\
\hline
\end{tabular}

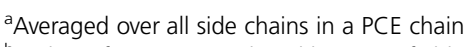

${ }^{\mathrm{b}}$ Radius of gyration predicted by mean-field model

'Hydrodynamic radius measured by a Viscotek GPC Max VE 2001 (Malvern Instruments Ltd, UK) in a mixed solvent of acetonitrile and water containing 0.10 M boric acid $\left(\mathrm{H}_{3} \mathrm{BO}_{3}\right) / 0.05 \mathrm{M}$ sodium hydroxide $(\mathrm{NaOH})$

stretched (rigid) due to the electrostatic repulsion between the negatively charged carboxylic acid groups. Contrastingly, in synthetic cement pore solution the backbones are significantly distorted and shrunken (flexible). Interestingly, in water the

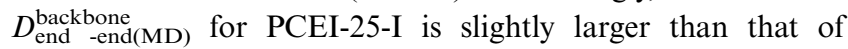
PCEI-25-II. However, it is significantly smaller than that in 


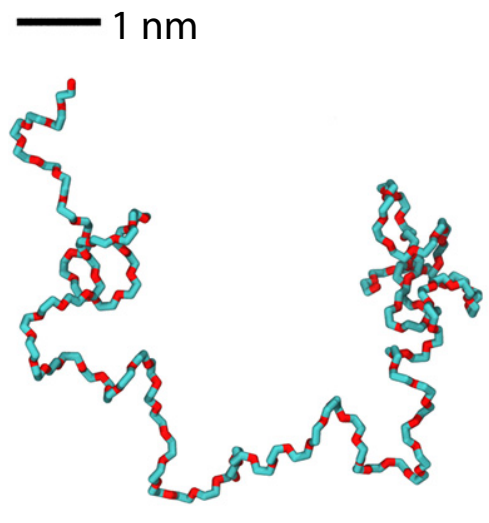

(a)

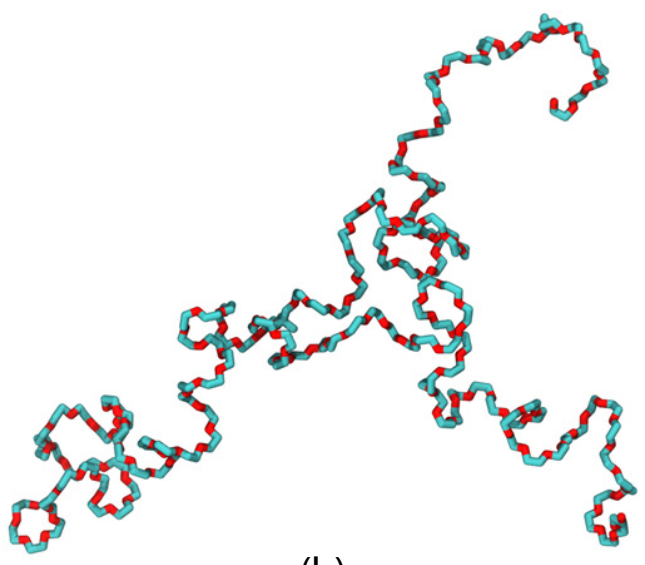

(b)

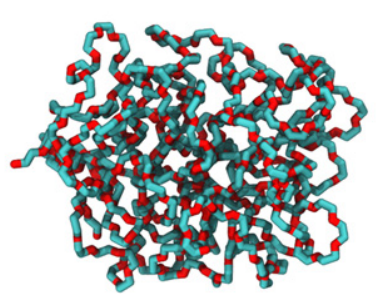

(c)

Figure 6. Conformations of multi-branched PEGs in synthetic cement pore solution: (a) PEG-100; (b) TMP-150; (c) sorbitol-300

synthetic cement pore solution, indicating that the congestion of the PEG side chains adjacent along the PCE backbone significantly affects the conformation of the PCEs as well.

Bailey et al. (1964) also demonstrated that PEO would form molecular association complexes with poly(acrylic acid) or poly(methacrylic acid) in an aqueous solution due to hydrogen bonding between ether oxygens and carboxyl groups at a low $\mathrm{pH}$ level of 4 to 10 and an ion-dipole interaction at higher $\mathrm{pH}$. However, the ion-dipole interaction disappears at $\mathrm{pH}$ levels greater than 7 in the presence of salts, such as sodium chloride $(\mathrm{NaCl})$. Therefore, formation of molecular associative complexes between PEG side chains and carboxylic groups can be ruled out here.

Next, the values of $R_{\mathrm{g}(\mathrm{MD})}$ and $R_{\mathrm{h}(\mathrm{MD})}$ obtained from simulations were compared with $R_{\mathrm{g}(\mathrm{mf})}$ and $R_{\mathrm{h}(\mathrm{VIS})}$, respectively. The $R_{\mathrm{g}(\mathrm{MD})}$ values for PCEM-25 and PCEI-25 are slightly smaller than $R_{\mathrm{g}(\mathrm{mf})}$ in water, whereas $R_{\mathrm{g}(\mathrm{MD})}$ of PCEA-34 is much smaller than $R_{\mathrm{g}(\mathrm{mf})}$. Arguably, the reason for that is that the mean-field model disregards the aggregation of PEG side chains, which, however, the simulation has shown is significant in PCEA-34.

In synthetic cement pore solution, the $R_{\mathrm{h}(\mathrm{MD})}$ values of the PCEs are a bit smaller than the experimental values of $R_{\mathrm{h}(\mathrm{VIS})}$ except for that of PCEA-34. This effect is probably caused by salting-out resulting from the higher ionic strength
$(I \approx 210 \mathrm{mM}$ and $150 \mathrm{mM}$ in synthetic cement pore solution and in the mobile phase used in the measurements, respectively) and higher $\mathrm{pH}$ value ( $\mathrm{pH}=13 \cdot 1$ and $12 \cdot 0$, respectively). However, as for PCEA-34, it is suggested that the denser PEG side chains present in PCEA-34 interact with each other even in water, producing a highly coiled polymer.

Lastly, the MD simulation of three types of multi-branch PEGs in synthetic cement pore solution showed that strong aggregation of the PEG branches is only observed for sorbitol300, which has six PEG branches linking to each $-\mathrm{OH}$ group in the sorbitol backbone, confirming that many PEG chains which are closely located are aggregated (Figure 6). In contrast, the PEG side chains in PEG-100 and TMP-150 do not aggregate and adopt stretched conformations. Table 4 lists $R_{\mathrm{h}(\mathrm{MD})}$ and $R_{\mathrm{h}(\mathrm{DLS})}$ in solutions. It suggests that in synthetic

Table 4. Hydrodynamic radius ( $\mathrm{nm}$ ) calculated by MD simulations and measured by DLS

\begin{tabular}{|c|c|c|c|}
\hline & PEG-100 & TMP-150 & SB-300 \\
\hline \multicolumn{4}{|l|}{ In water } \\
\hline$R_{\mathrm{h}(\mathrm{DLS})^{\mathrm{a}}}$ & $2 \cdot 25$ & $2 \cdot 32$ & $2 \cdot 58$ \\
\hline \multicolumn{4}{|c|}{ In synthetic cement pore solution } \\
\hline$R_{\mathrm{h}(\mathrm{MD})}$ & 1.60 & 1.95 & $1 \cdot 50$ \\
\hline$R_{\mathrm{h}(\mathrm{DLS})}{ }^{\mathrm{a}}$ & 1.69 & 1.98 & $2 \cdot 57$ \\
\hline
\end{tabular}

apolymer concentration is 0.5 wt. $\%$ 
Advances in Cement Research

Volume 29 Issue 10
Atomistic dynamics simulation to solve

conformation of model PCE

superplasticisers in water and cement

pore solution

Hirata, Branicio, Ye et al. cement pore solution PEG-100 and TMP-150 shrink, and the $R_{\mathrm{h}(\mathrm{MD})}$ values agree quite well with $R_{\mathrm{h}(\mathrm{DLS})}$; however, sorbitol-300 molecules are probably associated by intermolecular interaction during DLS measurement.

Therefore, the shrinking of the PCE backbone in synthetic cement pore solution is probably accelerated by the aggregation of the PEG side chains as well as the salting-out effect of the backbone itself.

Subsequently, the adsorbed conformation and the relationship with the cement-dispersing effect will be studied and reported in another paper. The authors expect that these simulations at the molecular level will shed light on the structure-property relationship and will be useful in the design of an even more effective next generation of PCE type superplasticisers.

\section{Conclusions}

The solution behaviour of three types of common PCE concrete superplasticisers (PCEM, PCEA and PCEI) in pure water and in synthetic cement pore solution was studied by atomistic MD simulations. The backbones of those PCEs are considerably stretched (rigid) in water due to the electrostatic repulsion between negatively charged carboxylic acid groups, whereas in synthetic cement pore solution the backbones are significantly distorted and shrunken (flexible) due to the aggregation of the hydrophobic PEGs as well as the salting-out effect on the backbone.

\section{Acknowledgements}

Dr Hirata wishes to express his deep gratitude to the Institute for Advanced Study for financing his research and stay at TU München under a Rudolf Diesel fellowship. Dr Hirata and Mr Tomike thank Mr Satoshi Ishida (Strategic Technology Research Center in Nippon Shokubai Co., Ltd, Japan) for fruitful discussions. Dr Branicio, Dr Ye, Dr Zheng and Dr Sullivan acknowledge the support of the A*Star Computational Resource Centre through the use of its highperformance computing facilities.

\section{REFERENCES}

Bailey FE Jr and Callard RW (1959) Some properties of poly(ethylene oxide) in aqueous solution. Journal of Applied Polymer Science 1(1): 56-62.

Bailey FE Jr, Lundberg RD and Callard RW (1964) Some factors affecting the molecular association of poly(ethylene oxide) and poly(acrylic acid) in aqueous solution. Journal of Polymer Science, Part A, Polymer Chemistry 2(2): 845-851.

Begum R and Matsuura H (1997) Conformational properties of short poly(oxyethylene) chains in water studied by IR spectroscopy. Journal of the Chemical Society, Faraday Transactions 93(21): 3839-3848.

Berendsen HJC, Spoel DVD and Drunen RV (1995) GROMACS: a message-passing parallel molecular dynamics implementation. Computer Physics Communications 91(1-3): 43-56.
Borget P, Galmiche L, Meins JFL and Lafuma F (2005) Microstructural characterisation and behaviour in different salt solutions of sodium polymethacrylate-g-PEO comb copolymers. Colloids and Surfaces A: Physicochemical and Engineering Aspects 260(1-3): 173-182.

de Gennes PG (1987) Polymers at an interface; a simplified view. Advances in Colloid and Interface Science 27(3-4): 189-209.

Devanand K and Selser JC (1991) Asymptotic behavior and long-range interactions in aqueous solutions of poly (ethylene oxide). Macromolecules 24(22): 5943-5947.

Flatt RJ and Bowen P (2006) Yodel: a yield stress model for suspensions. Journal of the American Ceramic Society 89(4): 1244-1256.

Flatt RJ, Schober I, Raphael E et al. (2009) Conformation of adsorbed comb copolymer dispersants. Langmuir 25(2): 845-855.

Gay C and Raphaël E (2001) Comb-like polymers inside nanoscale pores. Advances in Colloid and Interface Science 94(1-3): 229-236.

Hess B (2008) P-LINCS: a parallel linear constraint solver for molecular simulation. Journal of Chemical Theory and Computation 4(1): 116-122.

Hess B, Bekker H, Berendsen HJC and Fraaije JGEM (1997) LINCS: a linear constraint solver for molecular simulations. Journal of Computational Chemistry 18(12): 1463-1472.

Hess B, Kutzner C, Spoel DVD and Lindahl E (2008) GROMACS 4: algorithms for highly efficient, load-balanced, and scalable molecular simulation. Journal of Chemical Theory and Computation 4(3): 435-447.

Hirata T, Yuasa T and Nagare K (2000) Cement Admixture and Cement Composition. US Patent 6166112, Dec. assigned to Nippon Shokubai.

Houst YF, Bowen P, Perche F et al. (2008) Design and function of novel superplasticizers for more durable high performance concrete (superplast project). Cement and Concrete Research 38(10): 1197-1209.

Humphrey W, Dalke A and Schulten K (1996) VMD: visual molecular dynamics. Journal of Molecular Graphics 14(1): 33-38.

Jeknavorian AA, Roberts LR, Jardine L et al. (1997) Condensed polyacrylic acid-aminated polyether polymers as superplasticizers for concrete. In Proceedings of the 5th CANMET/ACI International Conference on Superplasticizers and Other Chemical Admixtures in Concrete (Malhotra VM (ed.)). American Concrete Institute, Farmington Hills, MI, USA, SP-173, pp. 55-81.

Jorgensen WL, Maxwell DS and Tirado-Rives J (1996) Development and testing of the OPLS all-atom force field on conformational energetics and properties of organic liquids. Journal of the American Chemical Society 118(45): 11225-11236.

Kauppi A, Andersson KM and Bergström L (2005) Probing the effect of superplasticizer adsorption on the surface forces using the colloidal probe AFM technique. Cement and Concrete Research 35(1): 133-140.

Kinoshita M, Suzuki T, Soeda K and Nawa T (1997) Properties of methacrylic water-soluble polymer as a superplasticizer for ultra high-strength concrete. In Proceedings of the 5th CANMET/ACI International Conference on Superplasticizers and Other Chemical Admixtures in Concrete (Malhotra VM (ed.)). American Concrete Institute, Farmington Hills, MI, USA, SP-173, pp. 143-162.

Kleshchanok D and Lang PR (2007) Steric repulsion by adsorbed polymer layers studied with total internal reflection microscopy. Langmuir 23(8): 4332-4339.

Lange A, Hirata T and Plank J (2012) The role of non-adsorbed PCE molecules in cement dispersion: experimental evidence for a new dispersion mechanism. In Proceedings of the 10th CANMET/ACI International Conference on Superplasticizers and Other Chemical Admixtures in Concrete (Malhotra VM (ed.)). American Concrete Institute, Farmington Hills, MI, USA, SP-288, pp. 435-449. 
Advances in Cement Research

Volume 29 Issue 10
Atomistic dynamics simulation to solve

conformation of model PCE

superplasticisers in water and cement

pore solution

Hirata, Branicio, Ye et al.
Lindahl E, Hess B and Spoel DVD (2001) GROMACS 3.0: a package for molecular simulation and trajectory analysis. Journal of Molecular Modeling 7(8): 306-317.

Linegar KL, Adeniran AE, Kostko AF and Anisimov MA (2010) Hydrodynamic radius of polyethylene glycol in solution obtained by dynamic light scattering. Colloid Journal 72(2): 279-281.

Mishra RK, Heinz H, Zimmermann J et al. (2012) Understanding the effectiveness of polycarboxylates as grinding aids. In Proceedings of the 10th CANMETIACI International Conference on Superplasticizers and Other Chemical Admixtures in Concrete (Malhotra VM (ed.)). American Concrete Institute, Farmington Hills, MI, USA, SP-288, pp. 235-249.

Mohan R, Jadhav V, Ahmed A et al. (2014) Effect of plasticizer additives on the mechanical properties of cement composite - a molecular dynamics analysis. International Journal of Chemical, Molecular, Nuclear, Materials and Metallurgical Engineering 8(1): 84-88.

Nawa T (2006) Effect of chemical structure on steric stabilization of polycarboxylate-based superplasticizer. Journal of Advanced Concrete Technology 44(2): 225-232.

Okamura H and Ouchi M (2003) Self-compacting concrete. Journal of Advanced Concrete Technology 1(1): 5-15.

Paas J, Müller MW and Plank J (2015) Influence of diester content in macromonomers on the performance of MPEG-based PCEs. In Proceedings of the 11th CANMET / ACI International Conference on Superplasticizers and Other Chemical Admixtures in Concrete (Malhotra VM (ed.)). American Concrete Institute, Farmington Hills, MI, USA, SP-302, pp. 199-210.

Pickelmann J, Li H, Baumann R and Plank J (2015) A ${ }^{13} \mathrm{C}$ NMR spectroscopic study on the repartition of acid and ester groups in MPEG type PCEs prepared via radical copolymerization and grafting techniques. In Proceedings of the 11th CANMET/ACI Conference on Superplasticizers and Other Chemical Admixtures in Concrete (Malhotra VM, Gupta PR and Holland TC (eds)). American Concrete Institute, Farmington Hills, MI, USA, SP-302, pp. 25-37.

Plank J, Li H, llg M et al. (2016) A microstructural analysis of isoprenol ether-based polycarboxylates and the impact of structural motifs on the dispersing effectiveness. Cement and Concrete Research 84: 20-29, https://doi.org/10.1016/j.cemconres.2016.02.010.
Sakai E and Daimon M (1997) Dispersion mechanisms of alite stabilized by superplasticizers containing polyethylene oxide graft chains. In Proceedings of the 5th CANMETIACI International Conference on Superplasticizers and Other Chemical Admixtures in Concrete (Malhotra VM (ed.)). American Concrete Institute, Farmington Hills, MI, USA, SP-173, pp. 187-201.

Shonaka M, Kitagawa K, Satoh H et al. (1997) Chemical structures and performance of new high-range water-reducing and air-entraining agents. In Proceedings of the 5th CANMET/ACI International Conference on Superplasticizers and Other Chemical Admixtures in Concrete (Malhotra VM (ed.)). American Concrete Institute, Farmington Hills, MI, USA, SP-173, pp. 599-614.

Shu X, Ran Q, Liu J et al. (2016) Tailoring the solution conformation of polycarboxylate superplasticizer toward the improvement of dispersing performance in cement paste. Construction and Building Materials 116: 289-298, https://doi.org/10.1016/j.conbuildmat. 2016.04.127.

Spoel DVD, Lindahl E, Hess B et al. (2005) GROMACS: fast, flexible, and free. Journal of Computational Chemistry 26(16): 1701-1718.

Teresa M, Laguna R, Medrano R et al. (2001) Polymer characterization by size-exclusion chromatography with multiple detection. Journal of Chromatography A 919(1): 13-19.

Tsubakimoto T, Hosoido M, Tawara H and Hirata T (1981) Cement Dispersant. Japanese Patent 1984-18338, Apr. assigned to Nippon Shokubai.

Uchikawa H, Hanehara S and Sawaki D (1997) The role of steric repulsive force in the dispersion of cement particles in fresh paste prepared with organic admixture. Cement and Concrete Research 27(1): $37-50$.

Winnefeld F, Becker S, Pakusch J and Götz T (2007) Effects of the molecular architecture of comb-shaped superplasticizers on their performance in cementitious systems. Cement and Concrete Composites 29(4): 251-262.

Yamamoto M, Uno T, Onda Y et al. (2004) Copolymer for Cement Admixtures and its Production Process and Use. US Patent 6727315, Apr. assigned to Nippon Shokubai.

Yoshioka K, Sakai E, Daimon M and Kitahara A (1997) Role of steric hindrance in the performance of superplasticizers for concrete. Journal of the American Ceramic Society 80(10): 2667-2671.

\section{How can you contribute?}

To discuss this paper, please submit up to 500 words to the editor at journals@ice.org.uk. Your contribution will be forwarded to the author(s) for a reply and, if considered appropriate by the editorial board, it will be published as a discussion in a future issue of the journal. 